\title{
Study of maternal and fetal outcome in postdate pregnancy in tertiary care hospital
}

\author{
Patel Yogeshkumar Pransukhbhai, Poonam Londhe*
}

Department of Obstetrics and Gynecology, GMERS Medical College, Dharpur, Patan, Ahmedabad, Gujarat, India

Received: 29 July 2020

Accepted: 19 August 2020

\section{*Correspondence:}

Dr. Poonam Londhe,

E-mail: bhaveshemmi@gmail.com

Copyright: (C) the author(s), publisher and licensee Medip Academy. This is an open-access article distributed under the terms of the Creative Commons Attribution Non-Commercial License, which permits unrestricted non-commercial use, distribution, and reproduction in any medium, provided the original work is properly cited.

\begin{abstract}
Background: Fetal, neonatal and maternal complications associated with pregnancy beyond 40 weeks have always been underestimated. However emerging evidence demonstrates that the incidence of complications increases after 40 weeks of gestation. The present study was conducted to find out the fetomaternal outcome of such prolonged pregnancy.

Methods: This was a prospective cross-sectional study of 70 patients with uncomplicated prolonged pregnancy fulfilling the inclusion and exclusion criteria and admitted in department of obstetrics and gynecology at a tertiary care hospital B. J. Medical College, Ahmedabad, Gujarat, India.

Results: Out of 70 patients, majority of the subjects belongs to $26-30$ years of age (50\%). The gestational age of $90 \%$ of patients were between $40-42$ weeks. About $42-44 \%$ of the foetus had a birth weight of 2.5-3.5 kgs. Maximum patients underwent vaginal deliveries in spontaneous group (57\%) and 64\% underwent LSCS in induced group. Mode of delivery is significantly associated with presence of adequate liquor.

Conclusions: With regular antenatal check-up, incidence of postdate pregnancy can be decreased and it is important because of definite risk to fetus as pregnancy continuing beyond 40 weeks of gestation is associated with increased perinatal morbidity and mortality especially those who do not come for regular antenatal check-up.
\end{abstract}

Keywords: Induction of labour, Perinatal morbidity, Prolonged pregnancy, Ultrasound

\section{INTRODUCTION}

Term pregnancy was defined as a pregnancy with gestational age from 3 weeks before till 2 weeks after the estimated date of delivery and post-term pregnancy as a pregnancy with a gestational age of 42 completed weeks or more. $^{1}$ In late 2012, a work group including representatives from the American college of obstetricians and gynecologists (ACOG), the society for maternal-fetal medicine (SMFM) and other professional societies recommended that the label "term" be replaced by early term, full term, late term and post-term to more accurately describe deliveries occurring at or beyond 37 weeks of gestation. Early term: 37, 0/7 weeks through 38, 6/7 weeks, full term: 39, 0/7 weeks through 40, 6/7 weeks, late term: 41, 0/7 weeks through $41,6 / 7$ weeks and post-term: $42,0 / 7$ weeks and beyond. ${ }^{2}$

The frequency of adverse neonatal outcome is lowest among uncomplicated pregnancies delivered between 39 and 40 weeks of gestation. The most frequent cause of prolonged pregnancy is inaccurate dating. ${ }^{3}$ Many inaccuracies exist using this method in women who have irregular cycles, have been on recent hormonal birth control, or who have first trimester bleeding. In particular, women are more likely to be oligo-ovulatory than polyovulatory, so cycles longer than 28 days are not uncommonly seen. The risk factors are primiparity, maternal genetic factors, prior post-datism, obesity and male gender of the fetus. ${ }^{4}$ Criteria for diagnosing 
postdates are correlation of menstrual history, clinical findings and USG. Ultrasonographic dating in early pregnancy can improve reliability of EDD. In postdate pregnancy there are chances of fetal hypoxia, asphyxia, intracranial damage, meconium aspiration syndrome, macrosomia, atelectasis, hypoglycemia and stillbirths fetal birth injurie, non-reassuring fetal heart rates. ${ }^{5}$ These perinatal risks increase with increase in the gestational age beyond 40 weeks. The maternal risks include an increase in labor dystocia, an increase in severe perineal injury and cervical tear related to macrosomia and operative vaginal delivery and an increase in the rate of caesarean delivery and postpartum hemorrhage. In the present study, fetomaternal outcome was studied in pregnancy beyond 40 weeks in consideration of spontaneous and induced labor. Management protocol for post term pregnancy is fetal surveillance for prolonged pregnancy, induction of labour, during intrapartum care proper monitoring of labour.

The objective of the study was to assess the role of antepartum fetal assessment in management of postdate pregnancy, to study role of induction in management of postdate pregnancy.

\section{METHODS}

This was a prospective study of 70 cases of postdates pregnancy. These patients were admitted in department of obstetrics and gynecology in the teaching institute, B J Medical College, Ahmedabad, with full term pregnancy with sure LMP during the period of June 2015 to November 2017, were studied for mode of delivery and maternal and fetal outcome in course of labour.

\section{Inclusion criteria}

Female patients of age between 18-35 years, with singleton pregnancy, sure LMP with previous regular menstrual cycle, cephalic presentation of the fetus with no medical disorder, and patients with previous caesarean section were included in the study.

\section{Exclusion criteria}

Patients with uncertain LMP, multiple pregnancy, mal presentation, contraindication to vaginal delivery, pregnancy with congenital malformation, intrauterine death, antepartum hemorrhage, polyhydramnios, eclampsia and subjects who are hypersensitivity to prostaglandin were excluded.

Study subjects were further divided according to duration of gestation in (40.01 to 42 weeks) and beyond 42 weeks. Patients were admitted in department of obstetrics and gynecology with reliable dates with 40 weeks of gestational age calculated by Naegle's formula. ${ }^{6}$ Detailed history and examination of all patients done before including them into study as shown in proforma. Further management of labour was carried out accordingly.
The data are collected using a prepared proforma meeting the objectives of the study by means of personal interview with the patients after taking informed consent.

Total 70 patients were selected according to the clinical examination of the patient. After per abdominal examination and per vaginal examination i.e. assessment of Bishop's score, every patient was studied under respective groups. Bishop score $\geq 6$ is regarded as a favorable cervix and score of $\leq 5$ regarded as unfavorable. $^{7}$ All 70 patients were divided under two groups. Group I included 33 patients which was labelled as spontaneous group. Group II, in which 37 patients were included and labelled as induction group.

On admission following investigations that include obstetric ultrasound, electronic fetal monitoring by cardio-tocography, non-stress test and biophysical profile and Doppler flow study were done. A patient was considered postdate, correlating her LMP (Naegele's rule), clinical examination and obstetric ultrasound findings.

In spontaneous group fetal heart rate record was kept half hourly in the first stage and every 15 minutes in the second stage of labor. After ARM, the color of liquor was noted, can be clear, meconium tinged, meconium stained, or thick meconium. If the liquor was thick meconium and spontaneous delivery was not possible, then the decision of LSCS was taken. If the liquor was meconium stained or meconium tinged then the decision of LSCS was taken according to the fetal heart rate after thorough monitoring. Fetal distress was defined as an abnormality of fetal heart rate necessitating that the obstetrician terminate labor by assisted vaginal delivery or caesarean section. Accordingly, the mode of delivery, maternal and perinatal outcome was studied.

Group II included the patients who were not in labor and were for the induction after evaluation. For induction, cervical ripening agents like dinoprostone gel or misoprostol tablets were used. Then the patients were observed for uterine contractions and strict fetal heart rate monitoring. After 6 hours of dinoprostone gel instillation or 4 hours of misoprostol tablet induction, per vaginal examination was done and repeated if needed with the same prerequisites. If cervix was favorable, oxytocin augmentation was done after assessing the uterine contractions. In both groups augmentation was done with amniotomy with good cervical dilatation and oxytocin drip started as per need. If per vaginal findings were same after second time of dinoprotone gel instillation or four times of misoprostol tablet induction, it was labelled as failure of induction, and decision of caesarean section was taken. The color of liquor was seen after amniotomy, if it was meconium tinged, stained or thick meconium, then the decision was taken same as discussed in group I and the maternal and fetal outcome was studied. Patients were followed up to 7 days after delivery; maternal and fetal morbidity or mortality was recorded. 


\section{Statistical analysis}

The data gathered of all 50 patients were analyzed using Microsoft excel and presented in number and percentages.

\section{RESULTS}

Table 1 presents the distribution of study subjects as per age group and gestational age. Majority of the subjects belongs to $26-30$ years of age (50\%). The gestational age of $90 \%$ of patients were between $40-42$ weeks. About $42-$ $44 \%$ of the foetus had a birth weight of $2.5-3.5 \mathrm{kgs}$.

Table 1: Demographic data of the patients $(n=70)$.

\begin{tabular}{|lll|}
\hline Variables & $\mathbf{N}$ & $\%$ \\
\hline Age in years & & \\
\hline $15-20$ & 9 & 12.8 \\
\hline $21-25$ & 23 & 32.8 \\
\hline $26-30$ & 35 & 50 \\
\hline More than 30 & 3 & 4.2 \\
\hline Gestational age in weeks & & \\
\hline 40 to 42 weeks & 63 & 90 \\
\hline More than 42 weeks & 7 & 10 \\
\hline Foetal birth weight & & \\
\hline Less than 2.5 & 2 & 2.85 \\
\hline $2.5-3.0$ & 30 & 42.85 \\
\hline $3.1-3.5$ & 31 & 44.28 \\
\hline $3.6-4.0$ & 7 & 10 \\
\hline
\end{tabular}

Table 2: Distribution of cases as per parity, amount of liquor and mode of delivery in both groups.

\begin{tabular}{|lllll|}
\hline \multirow{2}{*}{ Variables } & \multicolumn{3}{l}{ Groups } \\
& Spontaneous & \multicolumn{2}{l|}{ Induced } \\
\cline { 2 - 5 } & $\mathbf{N}$ & $\mathbf{\%}$ & $\mathbf{N}$ & $\mathbf{\%}$ \\
\hline Parity & & & & \\
\hline Primi & 17 & 51 & 20 & 54 \\
\hline $2^{\text {nd }}$ gravida & 7 & 21 & 11 & 29.7 \\
\hline $3^{\text {rd }}$ gravida & 7 & 21 & 3 & 8.1 \\
\hline $4^{\text {th }}$ gravida & 2 & 6 & 3 & 8.1 \\
\hline Amount of liquor & & & & \\
\hline Adequate (more than 10) & 21 & 55.3 & 23 & 71.8 \\
\hline AFI 5-10 & 11 & 29 & 8 & 25 \\
\hline AFI less than 5 & 6 & 15.7 & 1 & 3.2 \\
\hline Mode of delivery & & & & \\
\hline Vaginal & 19 & 57 & 13 & 36 \\
\hline LSCS & 14 & 43 & 24 & 64 \\
\hline
\end{tabular}

As shown in Table 2, majority of the patients were primigravida's in both groups. The amount of liquor was found to be adequate in most of the women. Maximum patients underwent vaginal deliveries in spontaneous group (57\%) and 64\% underwent LSCS in induced group.

Majority of mutigravida patients (47.3\%) in spontaneous group had duration of labour between 5-10 hours. About $50 \%$ of primigravida and $47.3 \%$ of multigravidas in induced group had duration of labour between 5-10 hours (Table 3).

Table 3: Duration of labour.

\begin{tabular}{|c|c|c|c|c|c|c|c|c|}
\hline \multirow{3}{*}{$\begin{array}{l}\text { Duration of } \\
\text { labour in hours }\end{array}$} & \multicolumn{4}{|c|}{ Spontaneous } & \multicolumn{4}{|c|}{ Induced } \\
\hline & \multicolumn{2}{|c|}{ Primigravida } & \multicolumn{2}{|c|}{ Multigravida } & \multicolumn{2}{|c|}{ Primigravida } & \multicolumn{2}{|c|}{ Multigravida } \\
\hline & $\mathbf{N}$ & $\%$ & $\mathbf{N}$ & $\%$ & $\mathbf{N}$ & $\%$ & $\mathbf{N}$ & $\%$ \\
\hline Up to 4 & 5 & 29.5 & 3 & 18.7 & 0 & 0 & 2 & 11.7 \\
\hline 5 to 10 & 5 & 29.5 & 7 & 43.7 & 10 & 50 & 8 & 47.3 \\
\hline 11 to 14 & 3 & 17.5 & 4 & 25 & 4 & 20 & 5 & 29.3 \\
\hline More than 15 & 4 & 23.5 & 2 & 12.6 & 6 & 30 & 2 & 11.7 \\
\hline Total & 17 & 100 & 16 & 100 & 20 & 100 & 17 & 100 \\
\hline
\end{tabular}

Table 4: Maternal outcome.

\begin{tabular}{|llllll|}
\hline Maternal outcome & & Spontaneous & \multicolumn{3}{c|}{ Induced } \\
\hline \multirow{3}{*}{ Type of delivery } & & $\mathbf{N}$ & $\mathbf{\%}$ & $\mathbf{N}$ & $\mathbf{\%}$ \\
& Vaginal & 19 & 57 & 13 & 36 \\
\cline { 2 - 6 } & LSCS & 14 & 43 & 24 & 64 \\
\hline \multirow{3}{*}{ Complication } & Vaginal laceration & 3 & 15.8 & 5 & 38.4 \\
\cline { 2 - 6 } & Perineal tear & 2 & 10.4 & 3 & 23 \\
\cline { 2 - 6 } & Cervical tear & 7 & 36.9 & 4 & 7.6 \\
\cline { 2 - 6 } & No complication & 7 & 53.1 & 15 & 46.9 \\
\hline Total & Episiotomy & 17 & 100 & 13 & 100 \\
\hline
\end{tabular}


Table 4 shows maternal morbidity. There was no serious maternal complication observed. Epistomy is the common complication observed in both groups

As shown in Table 5, mode of delivery is significantly associated with presence of adequate liquor.

Table 5: Correlation of amount of liquor and mode of delivery.

\begin{tabular}{|lll|}
\hline Liquor & LSCS & Normal delivery \\
\hline $\begin{array}{l}\text { Adequate (more } \\
\text { than 10) }\end{array}$ & N (\%) & N (\%) \\
\hline AFI 5-10 & $11(29)$ & $23(71.8)$ \\
\hline AFI less than 5 & $6(15.7)$ & $8(25)$ \\
\hline Total & 38 & 32 \\
\hline
\end{tabular}

\section{DISCUSSION}

In the present study, out of 70 cases 35 (50\%) fall in age group of 26-30 years. Although incidence of post maturity increases with increasing age, in present study maximum no. of patients are in age of 26 to 30 years. Higher proportion were in the gestational age of 40-42 weeks. These findings were comparable to the study by Kandalgaonkar et al. ${ }^{8}$

Maximum patients underwent vaginal delivery in spontaneous group and LSCS in induced group. This study findings are comparable to Gupta et al. ${ }^{2}$

In the present study, maximum no. of cases $(53 \%)$ were in primigravida group, $(47 \%)$ were in multigravida. In primigravida group $20(55 \%)$ out of 37 had to be induced and $17(45 \%)$ out of 37 were in spontaneous group. In multigravida group 16 were in spontaneous group and 17 were in induced group. Chhabra et al reported $68.66 \%$ of postdated women were primigravida and $31.34 \%$ multigravida in his study. ${ }^{9}$

Majority of patients (47.3\%) had duration of labour between 5-10 hours. Caughey et al reported duration of labour increases with increase in gestational age. ${ }^{10}$

LSCS rate in patients with spontaneous onset of labour was $43 \%$ while it was $64 \%$ in patients who were induced. And in vaginal delivery $57 \%$ patients were in spontaneous group and $36 \%$ were in induced group. In this study group shows the rate of LSCS increases with induction of labour $(64 \%)$ in compare with spontaneous group (43\%).

No significant morbidities were noted in the study in both the groups. Similar observation was seen in the study of Gupta et al. ${ }^{2}$ Episiotomy was done in maximum patients in both groups to prevent rupture of tissues.

\section{CONCLUSION}

With regular antenatal check-up, incidence of postdate pregnancy can be decreased and it is important because of definite risk to fetus as pregnancy continuing beyond 40 weeks of gestation is associated with increased perinatal morbidity and mortality especially those who do not come for regular antenatal check-up. Confirmation of diagnosis of exact term of pregnancy is very important as many patients don't have regular menstrual history and LMP. Diagnosis is confirmed by first trimester ultrasound which is most important non-invasive method and readily available. When there has been both a first and second trimester ultrasound, gestational age should be determined by earliest ultrasound. Majority of patients were between 26 to 30 years. Because most of patients came from lower socio-economical class and lower education in authors institute and they conceived at early age

\section{ACKNOWLEDGMENTS}

Authors would like to thank Dr. Parul, Dr. Nidhi and Dr. Niharika for their assistance and dedicated involvement in every step throughout the process, this paper would have never been accomplished.

Funding: No funding sources

Conflict of interest: None declared

Ethical approval: The study was approved by the Institutional Ethics Committee

\section{REFERENCES}

1. Alexander JM, McIntire DD, Leveno KJ. Forty weeks and beyond: pregnancy outcome by week of gestation. AM J Obstet Gynecol. 2000;96(2):291-4.

2. Gupta M, Shrivastava S, Rai S. To study the maternal and fetal outcome in pregnancy beyond 40 weeks. International $\mathrm{J}$ Clin Obst Gynaecol. 2020;4(2):123-9.

3. Neilson JP. Ultrasound for fetal assessment in early pregnancy. Cochrane Database Syst Rev. 2000;(2:CD000182).

4. Galal M, Symonds I, Murray H, Petraglia F, Smith R. Postterm pregnancy. Facts Views Vis Obgyn. 2012;4(3):175-87.

5. Morris JM, Thompson K, Smithey J, Gaffney G, Cooke I, Chamberlain P, et al. The usefulness of ultrasound assessment of amniotic fluid in predicting adverse outcome in prolonged pregnancy: A prospective blinded observational study. BJOG. 2003;110:989-94.

6. Frank Gaillard. Naegele's formula. Available at: https://radiopaedia.org/articles/naegeles-

formula\#: :text=The $\% 20$ Naegele's $\% 20$ formula $\% 20 \mathrm{i}$ s\%20simple,subtract\%203\%20months\%20(i.e\%20M arch). Accessed on $20^{\text {th }}$ February 2017.

7. Curran M. Bishop score calculator. Available at: http://perinatology.com/calculators/Bishop\%20Score 
\%20Calculator.htm. Accessed on $20^{\text {th }}$ February 2017.

8. Kandalgaonkar VP, Kose V. Fetomaternal outcome in postdated pregnancy. Int $\mathrm{J}$ Reprod Contracept Obstet Gynecol. 2019;8:1899-906.

9. Chhabra S, Dargan R, Nasare M. Postdate pregnancies: Management options. AM J Obstet Gynecol. 2007;57(4):307-10.

10. Caughey AB, Nicholson JM, Cheng YW, Lyell DJ, Washington AE. Induction of labor and cesarean delivery by gestational age. Am J Obstet Gynecol. 2006;195(3):700-5.

Cite this article as: Pransukhbhai YP, Londhe P. Study of maternal and fetal outcome in postdate pregnancy in tertiary care hospital. Int J Reprod Contracept Obstet Gynecol 2020;9:3585-9. 